\title{
PEMBERIAN ALAS DUDUK DAN MC KENZIE EXERCISE DAPAT MENURUNKAN KETEGANGAN OTOT DAN KELUHAN MUSKULOSKELETAL SERTA MENINGKATKAN PRODUKTIVITAS PADA PENGUKIR KENDANG TAMBUR DI UD. BUDI LUHUR GIANYAR
}

\author{
${ }^{1}$ Arfian Hamzah, ${ }^{2}$ Susy Purnawati, ${ }^{3}$ I Made Muliarta, ${ }^{4}$ Ida Bagus Adnyana Manuaba, \\ ${ }^{5}$ Nyoman Adiputra, ${ }^{6}$ Made Sudarma \\ ${ }^{1}$ Mahasiswa Program Studi Magister Ergonomi Fisiologi Kerja Universitas Udayana \\ ${ }^{2}$ Staff Dosen Departemen Ilmu Faal Universitas Udayana \\ ${ }^{3,4,5}$ Staff Dosen Program Studi Magister Ergonomi Fisiologi Kerja Universitas Udayana \\ ${ }^{6}$ Staff Dosen Program Studi Teknik Elektro Universitas Udayana
}

1.

\begin{abstract}
ABSTRAK
Karakteristik pengukir kendang tambur dilakukan dengan posisi duduk di lantai, sikap kerja membungkuk selama 8 jam dan 6 hari dalam seminggu. Hal inilah yang memicu timbulnya keluhan pegal yang dirasakan terutama pada bagian punggung bawah. Intervensi dengan pemberian alas duduk berupa matras serta upaya preventif berupa Mc Kenzie exercise dapat mengurangi ketegangan otot erector spinae dan keluhan muskuloskeletal akibat proses kerja. Penelitian ini bertujuan untuk membuktikan bahwa pemberian alas duduk dan Mc Kenzie exercise dapat menurunkan ketegangan otot dan keluhan muskuloskeletal serta meningkatkan produktivitas pada pengukir kendang tambur di UD. Budi Luhur Gianyar.

Penelitian ini merupakan true eksperimental, dengan rancangan sama subjek. Periode 1 subjek diberi perlakuan dengan kondisi kerja konvensional. Periode 2 subjek diberi perlakuan dengan pemberian alas duduk berupa matras dan Mc Kenzie exercise. Di antara ke dua tahap tersebut, diberikan washing out period dan adaptasi. Ketegangan otot erector spinae diukur dengan alat Surface Electromyography (SEMG), keluhan muskuloskeletal diukur dengan kuesioner Nordic Body Map dan produktivitas berdasarkan perbandingan antara input dan waktu dengan output. Efek intervensi dianalisis dengan uji Wilcoxon dan uji T-paired.

Hasil penelitian menunjukkan bahwa terjadi penurunan ketegangan otot erector spinae sebesar 21,39\% ( $<<0,05)$, penurunan keluhan muskuloskeletal sebesar 29,52\% $(\mathrm{p}<0,05)$ dan peningkatan produktivitas sebesar $22,13 \%(\mathrm{p}<0,05)$.

Dapat disimpulkan bahwa pemberian alas duduk dan Mc Kenzie exercise dapat menurunkan ketegangan otot dan keluhan muskuloskeletal serta meningkatkan produktivitas pada pengukir kendang tambur di UD. Budi Luhur Gianyar. Sehingga disarankan untuk diterapkan pada industri pengukir kendang tambur, untuk meminimalkan ketegangan otot dan keluhan muskuloskeletal akibat proses kerja mengukir.
\end{abstract}

Kata Kunci : Alas Duduk, Mc Kenzie Exercise, Ketegangan Otot erector spinae, Keluhan Muskuloskeletal, Produktivitas 


\section{ABSTRACT \\ THE APPLICATION OF MATRESS AND MC KENZIE EXERCISE DECREASE MUSCLE TENSION, MUSCULOSKELETAL COMPLAINTS AND INCREASE PRODUCTIVITY AMONG THE TRADITIONAL SMALL DRUM CARVERS IN UD. BUDI LUHUR GIANYAR}

The characteristics of the traditional small drum carvers are done by sitting on the floor, work with a bent position for 8 hours and 6 days a week. This is what triggers the incidence of sore muscle that is felt especially in the lower back. Interventions by mattress and Mc Kenzie exercise can reduce erector spinae muscle tension and musculoskeletal complaints due to work processes. This study aims to prove that sitting on the floor with matress and Mc Kenzie exercise can decrease muscle tension, musculoskeletal complaints and increase productivity among the traditional small drum carvers in UD. Budi Luhur Gianyar.

This study was a true experimental, with a treatment by subject design. The Period 1 subjects were treated by conventional working conditions. Period 2 subjects were treated by sitting with matress and Mc Kenzie exercise. Washing out period and adaptation has given between two stages. Tension of the erector spinae muscle was measured by Surface Electromyography (SEMG) instrument, musculoskeletal complaints was measured by Nordic Body Map and productivity based on input and time with output formula. Effect of intervention was analyzed by Wilcoxon test and T-paired test.

The results of this study was decrease in erector spinae muscle tension by $21.39 \%$ $(\mathrm{p}<0.05)$, decreased musculoskeletal complaints by $29.52 \%(\mathrm{p}<0.05)$ and productivity increase by $22.13 \%(\mathrm{p}<0.05)$.

It can be concluded that the application of matress and Mc Kenzie exercise can decrease muscle tension and musculoskeletal complaints and increase productivity among the traditional small drum carvers in UD. Budi Luhur Gianyar. So it suggested to apply it to the carvers of the industry drum to minimize muscle, tension musculoskeletal complaints due to the work of carving.

Keywords: Matress, Mc Kenzie Exercise, Muscle Tension erector spinae, Musculoskeletal Complaints, Productivity.

\section{PENDAHULUAN}

Kabupaten Gianyar dikenal sebagai daerah penghasil kerajinan dengan nilai seni tinggi. Satu diantaranya adalah kerajinan ukiran kayu kendang tambur tradisional yang kualitasnya dinilai salah satu yang terbaik di mancanegara.

Industri kerajinan kendang tabur masih dikelola secara manual. Pengaturan sistem kerja yang diterapkan masih belum profesional. Pekerja bekerja pukul 08.00 s.d pukul 17.00 WITA, dengan istirahat makan siang pukul 12.00 s.d pukul 13.00 WITA. Bekerja selama 6 hari dalam seminggu, dan libur pada hari Minggu dan hari raya.
Proses pembuatan kendang tambur berbahan kayu terdiri dari 3 tahap. Rangka kendang tambur yang sudah disediakan diukir secara manual dengan panjang pahat $25 \mathrm{~cm}$, lebar pisau bervariasi antar $0,5 \mathrm{~cm}$ sampai $4 \mathrm{~cm}$, palu dengan panjang $28 \mathrm{~cm}$ berat $\pm 1,5 \mathrm{~kg}$, dan tanpa alas duduk (duduk di lantai). Selanjutnya kendang tambur yang sudah diukir tersebut diwarnai dengan cat kayu agar lebih menarik. Proses terakhir adalah pemasangan kulit lembu dan pernak pernik penghias kendang tambur. Hasil akhir berupa kendang tambur dengan dimensi tinggi $20 \mathrm{~cm}$ dan diameter $9 \mathrm{~cm}$. Hasil wawancara dengan 
pemilik UD. Budi Luhur, dari ketiga tahap tersebut, diketahui bahwa proses pengukiran paling lama dan sulit dilakukan. Oleh karena itu, peneliti memutuskan untuk meneliti hanya pada proses pengukiran.

Berdasarkan hasil survey pendahuluan di bagian proses pengukiran, pekerja bekerja dengan posisi duduk di lantai, kaki menjepit kendang tambur, sikap kerja membungkuk dan secara berkelanjutan. Hal inilah yang memicu timbulnya keluhan pegal dan nyeri yang dirasakan terutama pada bagian punggung bawah.

Pekerjaan manual, khususnya pekerjaan yang berhubungan dengan kekuatan dan ketahanan tubuh manusia dalam pekerjaan yang dilakukannya dapat menyebabkan masalah yang selama ini diabaikan, diantaranya adalah nyeri punggung bawah (low back pain) yang disebut gangguan musculoskeletal. Penyebab hal ini karena postur kerja yang kurang fisiologis (kurang ergonomis), pengulangan gerakan (repetitive motion), postur kerja statis (static posture), sifat pekerjaan yang monoton, waktu bekerja yang cukup lama, dan sarana prasarana kerja yang tidak sesuai dengan antropometri pekerja (Simanjuntak, 2012).

Berdasarkan hasil kuesioner Nordic Body Map (NBM) dan 30 item kelelahan yang diberikan pada saat studi pendahuluan, pekerja cepat merasa lelah dan sering mengeluh kaku pada leher bagian atas sebesar $15 \%$, leher bagian bawah sebesar 17\%, dan punggung bawah sebesar 68\%. Sedangkan pada penelitian lain, otot yang besar peranannya dalam pekerjaan mengukir kayu adalah otot erector spinae (Putri, 2015). Ketegangan otot adalah kondisi yang ditandai dengan adanya peningkatan aktivitas listrik otot yang dapat diukur dengan surface electromyography (SEMG) (Shin \& Kim, 2007). Menurut Allen dkk. (2007) meningkatnya aktivitas listrik otot atau work average voltage muscle mencerminkan makin beratnya tegangan otot. Bertambahnya ketegangan otot akan mengganggu sirkulasi darah sehingga terjadi penimbunan sisa-sisa metabolisme. Penimbunan sisa metabolisme berupa asam laktat berhubungan dengan meningkatnya beban kerja, kelelahan, dan munculnya keluhan muskuloskeletal.

Sikap kerja membungkuk dalam keadaan statis dapat menimbulkan kondisi patologis pada sistem muskuloskeletal, seperti timbulnya keluhan Low Back Pain (LBP). LBP diartikan sebagai keluhan rasa tegang atau kaku pada otot di area atas lipatan gluteus inferior dengan atau tanpa nyeri menjalar ke tungkai (Koes dkk, 2006).

International Labour Office (ILO) yang bekerjasama dengan International Ergonomics Association (IEA), merekomendasikan bahwa untuk pekerjaan yang berulang-ulang sebaiknya digunakan peralatan khusus yang disesuaikan dengan kebutuhan operasi, penggunaannya aman, dan harganya murah sehingga bisa mempercepat operasi, dan dapat meningkatkan produktivitas. Berbagai faktor yang harus diperhatikan pada alat bantu kerja adalah seperti ukuran, dimensi, cara kerja, sikap kerja, agar sesuai dengan kemampuan, kebolehan, dan batasan pekerja (Manuaba, 1992; Suma'mur, 1995; Grandjean, 1998).

Perlu adanya kajian yang bersifat menyeluruh dengan pendekatan ergonomi total dalam upaya menyelesaikan masalah yang terdapat pada industri kendang tambur. Pendekatan ergonomi total menganjurkan partisipasi aktif semua pihak untuk menentukan masalah 
yang akan diperbaiki dan menentukan teknologi yang akan digunakan. Teknologi yang digunakan dalam susunan sistem kerja mengacu pada teknologi tepat guna. Pendekatan SHIP (Sistemik, Holistik, Interdisipliner, Partisipatori) dapat digunakan untuk mengatasi permasalahan yang ada agar dapat terwujud rancangan kerja yang kondusif dan diperoleh produk yang berkualitas sesuai dengan tuntutan zaman (Manuaba, 2005 ; 2003).

Melalui pendekatan partisipatori (participatory approach), seluruh komponen organisasi akan merasa terlibat, berkontribusi dan bertanggung jawab terhadap perbaikan yang dilakukan (Manuaba, 2006). Dalam penelitian ini pendekatan partisipatori yang dilakukan melalui pertemuan dengan perwakilan pengukir, sehingga ditemukan beberapa masalah yang dirasakan pekerja yang menjadi prioritas dan mungkin untuk dilakukan perbaikan. Hasil wawancara dengan 6 orang pengukir menyatakan bahwa pada pekerjaan mengukir terjadi gerakan membungkuk yang bersifat statis, dan alas duduk yang kurang mendukung.

Hasil pertemuan dengan perwakilan pengukir bahwa alternatif pemecahan masalah yang dapat dilakukan yaitu pemberian alas duduk dan upaya preventif untuk mengurangi dampak proses kerja. Mengingat pengukir bekerja di lantai dengan kaki menjepit kendang tambur, suatu perancangan alas duduk yang baik harus disesuaikan sedemikian rupa sehingga tulang duduk yang menyangga berat badan tidak berada pada permukaan yang keras dan berat badan tersebar pada daerah yang cukup luas. Alas yang tepat dapat mengurangi tekanan antar ruas tulang belakang terutama tulang punggung (lumbal).
Selain itu kombinasi berupa pemberian latihan tertentu sebagai upaya pencegahan dapat dilakukan. Pemberian latihan yang tepat dapat mengurangi rasa tidak nyaman pada otot, sehingga diperoleh rasa nyaman dalam bekerja yang akan berdampak pada kualitas kerja dan produktivitas yang baik (Tarwaka, 2011).

Salah satu bentuk latihan yang dapat diberikan adalah McKenzie Exercise. Prinsip McKenzie Exercise adalah memperbaiki postur untuk mengurangi ekstensi lumbal. Sedangkan secara operasional tujuan pemberian Mc Kenzie exercise untuk penguatan otot punggung bawah (otot-otot lumbosacral), mengurangi ketegangan otot erector spinae, meregangkan otot-otot yang memendek terutama otot-otot ekstensor punggung bawah, hamstring, dan otot quadratus lumborum, dan koreksi postur (McKenzie \& Kubey, 2000).

Dari uraian di atas kombinasi intervensi berupa pemberian matras dan McKenzie Exercise diharapkan dapat mengurangi ketegangan otot erector sipnae. Berkurangnya ketegangan otot tersebut ditandai dengan menurunnya voltage otot atau aktivitas listrik otot, yang dapat mempengaruhi menurunnya keluhan muskuloskeletal, serta meningkatkan produktivitas pada pekerja.

Penelitian ini bertujuan untuk: (1) membuktikan pemberian alas duduk dan Mc Kenzie exercise dapat menurunkan ketegangan otot erector spinae pada pengukir kendang tambur di UD. Budi Luhur Gianyar; (2) membuktikan pemberian alas duduk dan Mc Kenzie exercise dapat menurunkan keluhan musculoskeletal pada pengukir kendang tambur di UD. Budi Luhur Gianyar; (3) membuktikan pemberian alas duduk dan Mc Kenzie exercise dapat meningkatkan 
produktivitas pada pengukir kendang tambur di UD. Budi Luhur Gianyar.

\section{METODE PENELITIAN Rancangan Penelitian}

Penelitian ini merupakan true eksperimental dengan menggunakan rancangan sama subjek (treatment by subject design).

\section{Tempat dan Waktu Penelitian}

Penelitian ini akan dilakukan di UD. Budi Luhur, Kabupaten Gianyar, Bali. Waktu penelitian ini dilaksanakan dari bulan Agustus 2017 - Maret 2018.

\section{Populasi dan Sampel}

Populasi dalam penelitian ini seluruh pengukir kendang tambur di Kecamatan Sukawati, sedangkan populasi terjangkau dalam penelitian ini seluruh pengukir kendang tambur yang ada di UD. Budi Luhur sebanyak 12 orang. Sampel diambil menggunakan teknik total sampel.

\section{Variabel dan Instrumen Penelitian}

1. Pemberian alas duduk Pemberian alas duduk adalah saat bekerja pengukir kendang tambur memakai perlengkapan stasiun kerja berupa matras berukuran panjang $50 \mathrm{~cm}$ dan lebar $50 \mathrm{~cm}$ dengan menggunakan persentil 99, ketebalan $4 \mathrm{~cm}$, dengan lapisan luar matras $P V C$ leather sheet, dengan isi dalam matras berupa busa rebonded density 90 (FEOSH, 2008), dan selalu dipakai saat bekerja selama 9 minggu.

2. Mc Kenzie exercise adalah tehnik latihan yang bertujuan untuk memperbaiki postur kerja yang melibatkan gerakan badan terutama ke arah ekstensi. Latihan ini terdiri dari 4 gerakan masing-masing gerakan. Dosis latihan ini yaitu 3 repetisi, tahanan 1 menit, 1 set, dengan frekuensi $4 \mathrm{x}$ seminggu, selama 9 minggu. Total lama latihan adalah 15 menit/hari dilakukan sesaat sebelum istirahat makan siang, latihan ini dilakukan pada hari Senin, Rabu, Jum'at, dan Sabtu.

3. Ketegangan otot adalah aktivitas listrik yang terjadi pada otot erector spinae yang merupakan nilai persentase nilai ketegangan otot erector spinae saat kerja terhadap nilai ketegangan isometric otot erector spinae yang diukur menggunakan Surface Electromyography (SEMG).

4. Kuesioner Nordic Body Map digunakan untuk mengukur keluhan muskuloskeletal dengan 4 skala Likert.

5. Produktivitas kerja adalah perbandingan dari luaran (output) dan masukan (input) per satuan waktu.

\section{Analisis Data}

Data yang telah diperoleh selanjutnya diolah dan dianalisis dengan bantuan program SPSS versi 16.0 untuk menguji hipotesis yang telah ditetapkan dengan tahapan sebagai berikut:

1. Analisis deskriptif dengan menampilkan nilai rerata dan standar deviasi semua data lingkungan, ketegangan otot erector spinae, keluhan muskuloskeletal, dan produktivitas.

2. Uji normalitas menggunakan Shapiro Wilk dan uji homogenitas menggunakan Levene's Test.

3. Analisis komparabilitas rerata data lingkungan antara Periode 1 dan Periode 2 digunakan uji T-aired untuk parameter suhu, intensitas cahaya dan kebisingan. Sedangkan untuk parameter kelembaban digunakan uji Wilcoxon. Analisis komparabilitas rerata data keluhan muskuloskeletal 
pre antara Periode 1 dan Periode 2 digunakan uji Wilcoxon.

4. Analisis efek perlakuan rerata data ketegangan otot erector spinae antara Periode 1 dan Periode 2 digunakan uji T-paired, sedangkan analisis efek perlakuan rerata data keluhan muskuloskeletal post dan produktivitas antara Periode 1 dan Periode 2 digunakan uji Wilcoxon, begitu juga dengan rerata data selisih keluhan muskuloskeletal.

\section{HASIL PENELITIAN}

\section{Karakteristik Subjek Penelitian}

Tabel 1 Data Karakteristik Subjek Pengukir Kendang Tambur

\begin{tabular}{ll}
\hline Variabel & Rerata \pm SB \\
\hline Umur (th) & $28,67 \pm 1,073$ \\
Berat Badan $(\mathrm{kg})$ & $56,33 \pm 2,534$ \\
Tinggi Badan $(\mathrm{cm})$ & $1,671 \pm 0,014$ \\
Indeks Massa Tubuh & $20,15 \pm 0,787$ \\
Lama Kerja (th) & $4,33 \pm 1,073$ \\
\hline
\end{tabular}

Berdasarkan Tabel 1 diketahui rerata umur subjek dalam penelitian ini adalah 28,67 $\pm 1,073$ tahun. Didapatkan rerata indeks massa tubuh subjek adalah $20,15 \pm 0,787$, rerata tersebut masuk dalam kategori ideal.

\section{Kondisi Lingkungan Penelitian}

Tabel 2 Kondisi Lingkungan Kerja

\begin{tabular}{lccc}
\hline \multirow{3}{*}{ Parameter } & Periode 1 & Periode 2 & \\
\cline { 2 - 3 } & $\begin{array}{l}\text { Rerata } \\
\pm \text { SB }\end{array}$ & $\begin{array}{l}\text { Rerata } \\
\pm \text { SB }\end{array}$ & \\
\hline & 27,18 & 27,22 & \\
Suhu $\left({ }^{\circ} \mathrm{C}\right)$ & $\pm 0,354$ & $\pm 0,486$ & 0,621 \\
Kelembaban & 76,64 & 76,64 & \\
$(\%)$ & $\pm 0,048$ & $\pm 0,054$ & 0,564 \\
Intensitas & 258,6 & 259,2 & \\
Cahaya(lux) & $\pm 72,90$ & $\pm 80,52$ & 0,553 \\
Kebisingan & 60,8 & 60,8 & \\
(dB) & $\pm 1,720$ & $\pm 1,923$ & 0,785 \\
\hline
\end{tabular}

Berdasarkan Tabel 2 dapat dilihat hasil uji kemaknaan suhu, kelembaban relatif, intensitas cahaya, dan kebisingan tidak mempunyai perbedaan yang signifikan antara Periode 1 dan Periode 2. Hal ini menunjukkan bahwa kedua Periode tersebut memiliki karakteristik lingkungan yang sama.

\section{Normalitas Data}

Tabel 3 Hasil Uji Normalitas Data Keluhan Muskuloskeletal, Ketegangan Otot Erector Spinae dan Produktivitas

\begin{tabular}{|c|c|c|c|}
\hline Variabel & $\begin{array}{c}\text { Rerata } \\
\pm \mathrm{SB}\end{array}$ & Rentangan & $P$ \\
\hline $\begin{array}{l}\text { Kel. Musk. Pre } \\
\text { Periode } 1\end{array}$ & $\begin{array}{c}33,17 \\
\pm 0,718\end{array}$ & $32-34$ & 0,015 \\
\hline $\begin{array}{l}\text { Kel. Musk. Post } \\
\text { Periode } 1\end{array}$ & $\begin{array}{c}47,33 \\
\pm 0,492\end{array}$ & $47-48$ & 0,001 \\
\hline $\begin{array}{c}\text { Selisih Kel. } \\
\text { Musk. Periode } 1\end{array}$ & $\begin{array}{c}14,16 \\
\pm 0,492\end{array}$ & $13-15$ & 0,015 \\
\hline $\begin{array}{l}\text { Kel. Musk. Pre } \\
\text { Periode } 2\end{array}$ & $\begin{array}{c}33 \\
\pm 0,738\end{array}$ & $32-34$ & 0,020 \\
\hline $\begin{array}{l}\text { Kel. Musk. Post } \\
\text { Periode } 2\end{array}$ & $\begin{array}{c}37,18 \\
\pm 0,937\end{array}$ & $36-38$ & 0,002 \\
\hline $\begin{array}{c}\text { Selisih Kel. } \\
\text { Musk. Periode } 2 \\
\text { Ketegangan }\end{array}$ & $\begin{array}{c}4,18 \\
\pm 0,718\end{array}$ & $3,5-5$ & 0,015 \\
\hline $\begin{array}{l}\text { Otot erector } \\
\text { spinae }(\%) \\
\text { Periode } 1 \\
\text { Ketegangan }\end{array}$ & $\begin{array}{c}24,96 \\
\pm 0,498\end{array}$ & $24-25,5$ & 0,080 \\
\hline $\begin{array}{l}\text { Otot erector } \\
\text { spinae }(\%) \\
\text { Periode } 2\end{array}$ & $\begin{array}{c}19,62 \\
\pm 0,678\end{array}$ & $18,5-21$ & 0,498 \\
\hline $\begin{array}{l}\text { Produktivitas } \\
\text { Periode } 1\end{array}$ & $\begin{array}{c}0,197 \\
\pm 0,004\end{array}$ & $0,19-0,20$ & 0,001 \\
\hline $\begin{array}{l}\text { Produktivitas } \\
\text { Periode } 2\end{array}$ & $\begin{array}{c}0,253 \\
\pm 0,009\end{array}$ & $0,23-0,27$ & 0,035 \\
\hline
\end{tabular}

Tabel 3 menunjukkan bahwa beberapa data seperti ketegangan otot erector spinae pada Periode 1 maupun Periode 2 memiliki nilai $p>0,05$. Hal ini berarti bahwa data tersebut terdistribusi normal. Sehingga dalam analisis uji beda dilakukan dengan uji parametrik t-paired. Sedangkan data keluhan muskuloskeletal pada Periode 1 pre maupun post setelah dilakukan uji Shapiro-Wilk test tampak menunjukkan hasil bahwa data terdistribusi tidak normal (nilai $\mathrm{p}<0,05$ ), sehingga uji beda terhadap data keluhan 
muskuloskeletal pada Periode 1 pre maupun post dianalisis dengan uji nonparametrik Wilcoxon test.

Tabel 4 Hasil Uji Komparabilitas

Keluhan Muskuloskeletal

Menggunakan Uji Wilcoxon

\begin{tabular}{cccc}
\hline Variabel & Rerata \pm SB & Rentangan & $P$ \\
\hline Kel. Musk. & $33,25 \pm 0,621$ & $32-34$ & \\
Pre Periode 1 & & & 0,157 \\
Kel. Musk. & $32,83 \pm 0,717$ & $32-34$ & \\
Pre Periode 2 & & & \\
\hline
\end{tabular}

Berdasarkan Tabel 4 tersebut dapat diuraikan bahwa tidak ada perbedaan yang bermakna antara data pre Periode 1 dan pre Periode $2(p>0,05)$. Hal ini berarti bahwa tidak ada efek kondisi sebelumnya (Periode 1) yang mempengaruhi perubahan pada variabel tergantung, dan washing out cukup memberi efek pengembalian ke kondisi awal seperti pada kondisi pre Periode 1. Dengan demikian maka efek intervensi murni terjadi akibat perlakuan.

\section{Efek Perlakuan}

Tabel 5 Hasil Uji Efek Perlakuan

Menggunakan Uji T-paired dan Uji Wilcoxon

\begin{tabular}{cccc}
\hline Variabel & $\begin{array}{c}\text { Periode } 1 \\
\text { Rerata } \\
\end{array}$ & $\begin{array}{c}\text { Periode } 2 \\
\text { Rerata } \\
\pm \text { SB }\end{array}$ & $P$ \\
\hline Kel. Musk. & 47,33 & 37,18 & $0,002^{\mathrm{b}}$ \\
Post & $\pm 0,492$ & $\pm 0,937$ & \\
Selisih Kel. & 14,16 & 4,18 & $0,002^{\mathrm{b}}$ \\
Musk. & $\pm 0,492$ & $\pm 0,718$ & \\
Ketegangan & 24,96 & 19,62 & $0,001^{\mathrm{a}}$ \\
Otot erector & $\pm 0,498$ & $\pm 0,678$ & \\
spinae $(\%)$ & 0,197 & 0,253 & $0,002^{\mathrm{b}}$ \\
Produktivitas & $\pm 0,004$ & $\pm 0,009$ & \\
\hline
\end{tabular}

$\mathrm{a}=t$-paired

$\mathrm{b}=$ wilcoxon

Hasil uji beda seperti yang tampak pada tabel 5 di atas menunjukkan bahwa terdapat perbedaan yang signifikan antara ketegangan otot erector spinae pada
Periode 1 dengan Periode 2 dengan menggunakan uji $t$-paired. Demikian juga halnya dengan selisih keluhan muskuloskeletal dan produktivitas yang menunjukkan perbedaan bermakna antara Periode 1 dengan Periode 2 dengan menggunakan uji wilcoxon $(\mathrm{p}<0,05)$.

Analisis skor keluhan muskuloskeletal menunjukkan perbedaan yang bermakna antara Periode 1 dan Periode 2. Terdapat rerata penurunan skor keluhan muskuloskeletal sebesar $29,52 \%$.

\section{PEMBAHASAN}

Besarnya keluhan muskuloskeletal pada Periode 1 disebabkan adanya pembebanan pada punggung bawah, karena posisi pengukir dengan duduk di lantai, kaki menjepit kendang tambur, sikap kerja membungkuk dan secara berkelanjutan. Pheasant (2003) mengatakan bahwa pembebanan statis dapat menyebabkan aliran darah terhambat sehingga suplai nutrisi ke bagian otot tidak cukup. Keadaan tersebut menyebabkan akumulasi asam laktat yang pada akhirnya menyebabkan kelelahan pada otot skeletal yang dirasakan sebagai bentuk pegal otot pada pekerja.

Penelitian yang dilakukan oleh Akuthota dkk (2008), tentang Prinsip Core Stability Exercises, menunjukkan bahwa Program latihan penguatan otot core dapat mencegah LBP (Low Back Pain), menurunkan nyeri dan memperbaiki fungsi gerak pada pasien LBP. Penelitian lain yang dilakukan Alkuratu (2015), terdapat perbedaan yang signifikan pada penurunan keluhan low back pain myogenik pada kelompok kontrol dan kelompok perlakuan yang diberikan latihan core exercise, kelompok yang diberikan intervensi core exercise 
mengalami penurunan keluhan akibat LBP myogenik.

McKenzie Exercise menggunakan gerakan badan ke arah ekstensi serta peran aktif pekerja akan memulihkan mobilitas dan fungsi lumbal dengan menghilangkan stress yang akan mengembalikan nucleus pulposus kembali ke anterior, sehingga inflamasi yang terjadi pada ligament longitudinal posterior berkurang dan nyeri pada lumbal akan berkurang serta dapat memberikan rasa nyaman dan ada perbaikan postur serta menghilangkan imbalance mucle (McKenzie \& Kubey, 2000).

Pada penelitian ini ditemukan penurunan ketegangan otot erector spinae sebesar $21,39 \%$. Rerata nilai ketegangan otot erector spinae (\%) pada Periode 1 adalah 24,96 $\pm 0,498$ dan memurun pada Periode 2 menjadi $19,62 \pm 0,678$.

Penurunan nilai ketegangan otot erector spinae (\%) tersebut terjadi karena pemberian alas duduk berupa matras dengan tebal lapisan yang direkomendasikan oleh FEOSH (2008) dapat menurunkan ketegangan otot-otot sekitar panggul dan punggung bawah akibat adanya muscle guarding karena duduk di permukaan keras dan latihan dengan metode Mc Kenzie exercise menyebabkan otot-otot back extensor dapat mengalami rileksasi. Menurunnya ketegangan otot erector spinae terjadi karena menurunnya respon asetilkolin pada motor endplate. Keadaan tersebut berpengaruh pada pengeluaran ion kalsium yang adekuat dari t tubulus ke ruang intraseluler, ion kalsium yang adekuat ini menyebabkan berkurangnya kebutuhan ATP yang digunakan untuk ikatan aktin-myosin. Sehingga fleksibilitas ikatan aktin-myosin kembali dalam keadaan fisiologis (Irfan, 2008).
Ketegangan otot erector spinae secara terus menerus ini menyebabkan pergeseran pelvis menjadi Anterior Tilt, akibatnya terjadi kompenasasi pada otot quadriceps (Quad Dominance). Kerja yang berlebihan pada otot quadriceps bisa menyebabkan nyeri pada lutut (Patellofemoral Pain Syndrome) (Panjabi $\&$ White, 2001).

Hasil serupa pada hasil penelitian Muliarta (2014) menyatakan bahwa perbaikan sikap dan posisi kerja tukang bangunan pada proses angkat-angkut material bangunan mengurangi aktivitas listrik otot erector spinae sebesar $88,90 \%$ dan keluhan musculoskeletal sebesar 22,92\%. Hasil penelitian Mulyono (2010) menyatakan sebesar $60 \%$ dari populasi sampel menyebutkan bagian dudukan kursi kuliah yang keras berdampak langsung terhadap nyeri pada bagian pantat dan punggung bawah.

Analisis produktivitas didapatkan adanya perbedaan yang bermakna produktivitas Periode 1 dan Periode 2. Pada penelitian ini terdapat peningkatan produktivitas sebesar 22,13\%. Rerata produktivitas Periode 1 adalah 0,197 $\pm 0,004$ dan pada Periode 2 adalah $0,253 \pm 0,009$.

Hal ini menunjukkan bahwa pemberian matras dan Mc Kenzie Exercise efektif dalam meningkatkan produktivitas kerja pengukir kendang tambur. Hal ini sejalan dengan hasil penelitian Dhari (2016) bahwa pemberian terapi latihan dan modifikasi kondisi kerja dapat meningkatkan produktivitas kerja pada pembatik cap.

\section{SIMPULAN DAN SARAN Simpulan}

Berdasarkan hasil analisis dan pembahasan yang telah dijabarkan sebelumnya, dapat disimpulkan bahwa. 
1. Pemberian alas duduk dan Mc Kenzie exercise dapat menurunkan ketegangan otot erector spinae pada pengukir kendang tambur di UD. Budi Luhur Gianyar sebesar 21,39\%

2. Pemberian alas duduk dan Mc Kenzie exercise dapat menurunkan keluhan muskuloskeletal pada pengukir kendang tambur di UD. Budi Luhur Gianyar sebesar $29,52 \%$

3. Pemberian alas duduk dan Mc Kenzie exercise dapat meningkatkan produktivitas pada pengukir kendang tambur di UD. Budi Luhur Gianyar sebesar $22,13 \%$.

\section{Saran}

Berdasarkan simpulan di atas maka dapat disarankan beberapa hal sebagai berikut.

1. Pemberian alas duduk dan Mc Kenzie Exercise disarankan untuk dapat diterapkan pada industri pengukir kendang tambur, agar dapat meminimalkan keluhan yang ditimbulkan akibat proses kerja mengukir.

2. Penelitian berikutnya dapat dilakukan dengan memberikan masing-masing intervensi secara terpisah, untuk mengetahui intervensi yang lebih memberikan efek pada keluhan yang ditimbulkan akibat proses kerja mengukir.

3. Hasil dari penelitian ini dapat dipakai sebagai referensi bagi penelitian yang sejenis dan bagi peneliti bisa juga dikembangkan kearah yang lebih mendalam.

\section{DAFTAR PUSTAKA}

Akuthota, V., F. Michael., A. Ferreiro, T. Moore. 2008. Core stability Exercise Principles. Curr.Sports Med.Rep., Vol.7, No.1.

Alkuratu, L.C. 2015. Pengaruh Core Stablity Exercise Secara Kelompok dan Individu Terhadap Low Back Pain
Myogenik pada Pembuat Batu Bata di Desa Maron. Skripsi: Fakultas Imu Kesehatan. Universitas Muhammadiyah Surakarta.

Allen, D.G., Lamb, G.D., Waterblad, H. 2007. Skeletal Muscle Fatigue. Cellular Mechanisms. (cited 2017 Sept. 14).

Dhari, I F W. 2016. Pemberian Pilates Exercise dan Modifikasi Kondisi Kerja Dapat Menurunkan Keluhan Subjektif dan Meningkatkan Produktivitas Kerja pada Pembatik Cap di Industri Batik. (tesis). Denpasar: Program Pascasarjana Universitas Udayana.

FEOSH. 2008. Creating a Healthy Workstation Environment. Available at

URL:http//www.eh.doe.gov/feosh/pub s/ergo-12-10.pdf. Diakses 11 Sept 2017.

Irfan, M. 2008. Beda Pengaruh Auto Stretching dengan Contract Relax and Stretching Terhadap Penambahan Panjang Otot Hamstring. Jurnal Fisioterapi Indonusa Vol. 8 No. 1.

Manuaba, A. 2005. Total Ergonomic Productivity, Product Quality and Customers Satisfaction. Prosiding Seminar Nasional ke II untuk Peningkatan Kualitas Sistem Manufaktur dan Jasa. Yogyakarta, 30 April 2005.

Manuaba, A. 2006. Macro Ergonomics Approach on Work Organizations with Special Reference to the Utilization of Total Ergonomic SHIP Approach to Obtain Humane, Competitive and Sustainable Work System and Products. Prosiding Seminar Nasional Ergonomi. Surabaya, 21-22 November 2006.

McKenzie, R., dan Kubey, C. 2000. Steps To A pain-Free Life. New York: 
Dutton Book Published by Penguin Group.

Muliarta, I.M. 2014. Perbaikan Cara Angkat-Angkut Material Bangunan Mengurangi Aktivitas Listrik Otot Erector Spinae dan Keluhan Muskuloskeletal Tukang Bangunan. Online Journal System Universitas Udayana.

Mulyono, G. 2010. Kajian Ergonomi pada Fasilitas Duduk Universitas Kristen Petra Surabaya. Jurnal Universitas Kristen Petra Surabaya. Dimensi Interior.

Panjabi, M., dan White, A. 2001. Biomechanics in the Musculoskeletal System. Churchill Livingstone. New York.

Pheasant, S. 2003. Ergonomics, Work and Health. London: Macmillan Acsdemic Profesional Ltd.

Putri, P.D.W. 2015. Perbaikan Stasiun Kerja Menurunkan Aktivitas Listrik Otot dan Keluhan Muskuloskeletal pada Perajin Ukir Kayu di Desa Batuan Gianyar Bali. Jurnal Universitas Udayana. Fakultas Kedokteran.

Shin, H.J., dan Kim, J.Y., 2007. "Measurement of trunk muscle fatigue during dynamic lifting and lowering as recovery time changes". International Journal of Industrial Ergonomics 37, 545-551.

Simanjuntak, R.A. 2012. Penilaian Faktor-Faktor Resiko pada Saat Melakukan Pekerjaan dengan Metode Manual Task Risk Assessment. Prosiding Seminar Nasional Aplikasi Sains dan Teknologi (SNAST) Periode III; 20123 November; Yogyakarta; 2012.

Tarwaka, S.H.A. 2011. Ergonomi Industri: Dasar-dasar pengetahuan ergonomi dan aplikasi di tempat kerja. Cetakan kedua. Surakarta : Harapan Press Solo. 